\title{
NOTAS DE TALLER SOBRE RICHARD JONES
}

\author{
CARLOS RODRIGUEZ BRAUN \\ Universidad Complutense de Madrid
}

Sugiero que en próximas Jornadas adoptemos un criterio de uso frecuente en reuniones académicas internacionales y establezcamos, aparte las ponencias y comunicaciones, una tercera sección: el taller. Allí no se expondrían trabajos terminados, sino, como su nombre indica, trabajos en curso work in progress. Predicaré con el ejemplo y describiré brevemente aquella parte de mi taller de historiador del pensamiento económico denominada «Richard Jones».

Las obras del reverendo Richard Jones (1790-1855) - que no han sido nunca vertidas al español - son de difícil acceso en nuestras bibliotecas, que en contados casos registran el Essay on the distribution of wealth de 1831. pero no sus trabajos publicados posteriormente ni los Literary remains que aparecieron después de su muerte en 1859 , editados por su amigo William Whewell.

Los manuales de nuestra disciplina retratan a Jones como ilustre antiricardiano y precursor del pensamiento económico historicista, institucionalista y marxista - cabría añadir: estructuralista-. Una parte de mi trabajo con relación a Jones, basado en el segundo ejercicio del concurso para obtener la plaza de profesor titular, es un artículo de carácter divulgatorio y general sobre su vida y obra, que tengo ya bastante avanzado y que será publicado en Información Comercial Española *.

Dos aspectos centrales del pensamiento de Jones han recibido atención por parte de nuestros colegas extranjeros: su visión metodológica próxima al inductivismo y su teoría de la renta opuesta al esquema de Ricardo. Pero tengo en mi taller otras líneas de investigación que quedan abiertas; resumiré a continuación cuatro de ellas.

1) Jones pasó muchos años de su vida, de 1831 a 1851, colaborando en la llamada Reforma de Russell de 1836, de conmutación de los diezmos,

\footnotetext{
* Se refiere al artículo que ha aparecido recientemente en el núm. 656 (abril 1988) de esa revista.
} 
y después como uno de los tres comisionados supervisores. No he encontrado bibliografía sobre sus actividades a este respecto.

2) Jones y Mill. Si Jones tuvo la desgracia de oponerse a la escuela que finalmente se impondría en la ciencia económica el ricardianismo. sufrió otra desgracia adicional de la que también era inocente: fue injustamente desvalorizado por J. S. Mill, quien en sus Principios de economía política redujo al reverendo Jones a rôle menor de acumulador de datos. Tal diagnóstico no se tiene en pie porque cualquiera que lea el capítulo IV del libro II de los Principios verá que Mill adopta el esquema del Essay de Jones, sus mismas categorías y sus mismos objetivos. Si hubo alguien que enseñó a Stuart Mill la importancia económica de las formas concretas de los derechos de propiedad, ése fue Richard Jones.

3) Jones el precursor. Hay desacuerdo entre los especialistas acerca del grado en que Jones influyó entre historicistas ingleses y alemanes e institucionalistas norteamericanos. Cabría una investigación sobre en qué medida su influencia, reconocida por todos, fue una proclamación a posteriori.

4) Jones y Marx. Difícil es encontrar a dos economistas tan distintos, personal y doctrinalmente, como Marx y el reverendo Jones. Sin embargo, Marx lo elogia en El Capital, le presta mucha atención en la Historia crítica de las teorias de la plusvalía y le atribuye el alumbramiento o la defensa de muchas ideas correctas. Numerosos autores han destacado el papel de Jones como raíz del pensamiento marxista. Sobre este punto, que merece un trabajo de investigación por sí mismo, no he podido localizar todavía un texto que conjeturo crucial; se trata de un artículo que el conocido economista austromarxista Rudolf Hilferding publicó en Die neue Zeit en 1900. Mi propósito es analizar, a partir de este artículo, el presunto "marxismo» de Jones, sobre el que han puesto énfasis conocidos especialistas del siglo actual, como Eric Roll y Henryk Grossman (Margot Alonso y Carlos Rodríguez Braun, "La variante marxista de Richard Jones. Una nota», en Moneda y Crédito, núm. 185, junio 1988). 


\section{EL DEBATE DE LA LEY DE REFORMA \\ DE LOS ARANCELES DE 1841: \\ LIBRECAMBISTAS FRENTE \\ A PROTECCIONISTAS}

ROGELIO VELASCO

Universidad de Málaga

En este trabajo se intenta poner de relieve los orígenes de la actuación en el Congreso de los Diputados, de manera organizada, del grupo de presión librecambista. Pasaremos revista, en primer lugar, a los problemas clave que se debatieron en las legislaturas anteriores a $1841 \mathrm{y}$ a las polarizaciones de intereses que se manifestaron, en un resumen desesperadamente abreviado. En segundo lugar, nos detendremos en el dictamen que informó a dichas ley, elaborado por Manuel Sánchez Chaves, Manuel María Gutiérrez y Eusebio María del Valle. En tercer lugar, comentaremos las cuestiones que atrajeron la atención de los diputados en la discusión parlamentaria y la homogeneidad de acción de los partidarios de una mayor liberalización comercial.

\section{Antecedentes en los debates de anteriores legislaturas}

En las Cortes de Cádiz la política de abastos dominó la escena legislativa, centrándose la discusión en torno al precio del cereal doméstico para la admisión del extranjero. No se observan grupos de intereses organizados y enfrentados.

Durante las Cortes del Trienio, tanto en la Ley de Bases de Reforma de los Aranceles como en las de prohibición de entrada de frutos y en la de algodones, son los diputados americanos, con Freire a la cabeza (y un Lucas Alamán enmudecido), los que protagonizan la discusión en defensa de sus intereses comerciales, sólo compatibles con la liberalización comercial. En la ley de algodones, el diputado Martínez de la Rosa se erige en defensor de los agricultores del sur de Granada, pero su intervención es a título individual, sin ningún alineamiento por afinidad ideológica o geográfica.

En la revisión de la ley que se llevó a cabo en 1821, las disensiones se producen entre los propios diputados catalanes, que hasta entonces habian mostrado su comportamiento monolítico. El diputado Oliver, abanderado 
del prohibicionismo y con intereses navieros (junto a armadores de Mahón) consigue sacar adelante una reforma de ley por la que se rebaja el tonelaje mínimo de los barcos para reexportar mercancías e importar duelas, con lo que se facilitaba el contrabando marítimo. Con anterioridad había combatido el contrabando y sus causas, que ahora se posibilitaban.

A partir de las Cortes del Estatuto Real, en 1834, se inicia un proceso de creación y supresión de juntas de aranceles y de comisiones revisoras, públicas y reservadas, que elaboraron diversos informes y que culmina con la presentación a las Cortes del proyecto de ley el 13 de mayo de 1841 .

En este proceso se solicita con carácter generalizado la opinión sobre la reforma arancelaria a grupos no vinculados directamente a la administración: Juntas de Comercio, profesores de universidad, industriales y agricultores.

\section{El informe de la Comisión Reservada}

El informe se vertebra en torno a tres cuestiones.

\subsection{El concepto de protección.}

Exención a las primeras materias y bienes de capital para la industria. Sólo consideraban que los productos estaban protegidos cuando el precio final del producto extranjero - con arancel- superaba al nacional.

\subsection{Defensa de la metalurgia basado en el informe de «La Constancia» de M. A. Heredia.}

Solicitaban una elevación de la tarifa de los flejes y una reducción de las de duelas. De esta forma se hacían compatibles los intereses de fabricantes de flejes y de envasadores de caldos. La maquinaria para las fábricas metalúrgicas veían reducidos sus derechos entre el 2 y el 4 por 100; los consumidores no podían soportar un arancel mayor y los fabricantes contaban ya con suficiente protección.

2.3. Reducción de los derechos de importación del algodón y probibición de toda manufactura de algodón extranjero. 
3. La discusión en el Congreso de la ley

El 13 de mayo de 1841, el diputado Cesáreo María Sáenz solicita que el Gobierno envíe al Congreso los trabajos y proyecto de ley de reforma arancelaria.

Días más tarde, el 6 de junio, la Comisión de Aranceles presenta el informe con el voto particular de Sánchez Silva, diputado por Cádiz, que proponía incluir en la discusión el problema algodonero y establecer un tratado de comercio con Inglaterra; se trataba de admitir manufacturas de algodón a cambio de una rebaja del 15 por 100 para vino, aceite y frutas en el arancel británico.

La Comisión no contemplaba en su informe modificar la legislación sobre algodones. Esta comisión, junto a diputados partidarios de las prohibiciones. argüían:

1. El intercambio de productos manufacturados por agrícolas es desigual en valor añadido, aunque tenga valores de cambio equivalentes.

2. La capacidad de absorción de productos agrícolas por Inglaterra estaba limitada por los gustos, los productos sustitutivos y la población.

3. Había que esperar a la ampliación del mercado interior para que se desencadenara el proceso de incremento del consumo-introducción de técnicas-reducción de precios.

4. La realización del tratado supondría una cesión de soberanía a Inglaterra, que sólo reside en las Cortes.

En la revisión del arancel llevado a cabo en 1842, es el grupo de diputados andaluces en bloque el que solicita la discusión del problema algodonero.

Sánchez Silva continúa de portavoz, aunque ha flexibilizado sus posiciones. Ya no habla de «tratado de comercio», sólo de una admisión de algodones a cambio de productos agrícolas, proponiendo un 30 por 100 como tarifa para los géneros admitidos. Esgrime como argumento que el arancel es obra de moderados (1841) y ahora gobiernan los progresistas (1842).

Los diputados catalanes y el propio Ministro de Hacienda Surrá y Rull emplean una táctica dilatoria: hay que reunir más datos e informes. Advierten con la desobediencia de las masas de trabajadores a aceptar cualquier acuerdo comercial con Inglaterra.

Al contrario de lo que ocurrió cuando fue aprobada, el equilibrio de fuerzas es mucho mayor en la revisión de la ley. En la primera votación hay un empate a 56 votos, en la segunda el resultado fue 67 a 63, favorable 
a los que eran contrarios a la admisión de géneros de algodón. Había comenzado a fraguarse el pacto arancelario de 1849.

Hemos visto cómo con anterioridad a esta ley de aranceles no se advierte una organización en el grupo partidario de la liberalización comercial. A raíz de la discusión en el Congreso de la ley de 1841 , se nos aparece un grupo homogéneo ante las prohibiciones que actúan no ya de forma aislada en defensa de intereses locales o provinciales, sino coordinadamente, entre miembros de diverso pelaje político y distinta procedencia regional. El hecho de que la presencia en las Cortes de 1842 fuera abrumadoramente progresista denota la divergencia entre ideología política y económica en relación con el comercio exterior, con todos sus supuestos y consecuencias, aunque hay que matizar que el modelo de Estado era, básicamente, coincidente entre los dos grupos en liza, progresistas y moderados. 